ORIGINAL ARTICLE

\title{
Attributable risk of alcohol and other drugs for crashes in the transit industry
}

\author{
C B Cunradi, D R Ragland, B Greiner, M Klein, J M Fisher
}

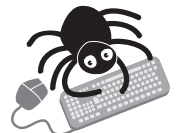

Table 3 is available on our website.

See end of article for authors' affiliations

.....................

Correspondence to: Dr C B Cunradi, Prevention Research Center, Pacific Institute for Research and Evaluation, 1995

University Avenue \# 450

Berkeley, CA 94704, USA:

cunradi@prev.org

Accepted 9 August 2005

Injury Prevention 2005;11:378-382. doi: 10.1136/ip.2004.007476

Objective: To estimate the impact of employee alcohol and drug use on crashes in the transit industry from 1995-2000.

Design: Secondary analysis of federally mandated post crash and random alcohol and drug testing results.

Setting: The US transit industry.

Subjects: Transit industry employees.

Main outcome measures: Relative risk (RR), population attributable risk (PAR), and population attributable risk percentage (PAR\%).

Results: For alcohol testing, the estimated PAR\% ranged from $0.02 \%$ (1999) to $0.03 \%$ (1995). For drug testing, the estimated PAR\% ranged from $0.38 \%$ (1998) to $0.67 \%$ (1997). Based on these calculations, the estimated number of crashes per 1000 crashes attributable to alcohol was less than one during 1995-2000, and the number attributable to drugs ranged from about four to about six. The number of crashes attributable to either alcohol or drugs did not vary greatly from 1995-2000. Estimated rates of crashes attributable to alcohol or drugs were substantially lower in 1995, the first year of testing, than had been projected based on previous estimates, and did not show substantial change from 1995-2000.

Conclusions: Approaches to transit safety based on reducing employee use of alcohol and other drugs have modest potential for reducing number of fatalities, injuries, and crashes.

I a 1991 New York City subway crash that resulted in five deaths and about 200 injuries, the train operator was intoxicated and later found to have a blood alcohol level of 0.21 , considerably higher than the legal limit for operating a motor vehicle. ${ }^{1}$ This tragic event, along with several other incidents, spurred a legislative process that ultimately led to the implementation of a comprehensive program of drug and alcohol testing in most segments of the transportation industry, including the Omnibus Transportation Employee Test Act of 1991. ${ }^{23}$ In April 1994, implementation guidelines were published by the Federal Transit Administration (FTA) requiring mandatory drug and alcohol testing for all safety sensitive employees in urban mass transit agencies that received funds from the Department of Transportation (DOT). The regulations have implications specifically for controlling the influence of alcohol and drugs on the transit industry and potentially for controlling the influence of drugs and alcohol at worksites in general.

Although events such as the New York City subway crash in 1991 are clearly of public concern, scant data are available to indicate the actual impact of alcohol and other drug use on safety in the transit industry. In 1993, a study that assessed the potential beneficial impact of alcohol and drug testing on the transit industry presented only limited data. ${ }^{4}$ Based partially on these data, regulations for mandatory alcohol and drug testing were implemented in January 1995. Large operators (defined as those who primarily operate in urban areas with populations of 200000 or more) were required to begin their drug and alcohol testing programs on 1 January 1995, and to report their results to the FTA. All other operators were required to have programs in place on 1 January 1996. The regulations mandated a system of record keeping and reporting concerning the number, type, and results of tests. These data provide the basis for estimating the role of employee alcohol and drug use in transit industry crashes, and for evaluating the potential benefits of alcohol and drug testing within this workforce.

The aim of this study is to estimate the number and percentage of crashes in the transit industry that could be attributed to alcohol or other drug use through the calculation of the population attributable risk (using empirical data collected from 1995-2000 as part of the federally mandated record keeping system).

\section{MATERIALS AND METHODS}

Data acquisition

Data on post crash and random drug and alcohol testing results among transit industry employees from 1995-2000 were obtained from annuals reports published by the US DOT. ${ }^{5-10}$ Percent positive drug and alcohol test results are based on the number of positive results divided by the number of specimens collected for each.

\section{Testing protocols}

Employees who perform safety sensitive functions became subject to mandatory alcohol and drug testing, including those involved in revenue vehicle operation, maintenance, and dispatch; those with a commercial driver's license for non-revenue vehicle operation; and armed security personnel. The regulations call for several types of testing including testing for cause and pre-employment, random, post crash, and return-to-work testing. There is no direct measure of testing uniformity. Compliance with the FTA's testing program, however, is a condition of Federal assistance. The total number of random tests conducted must equal at least $50 \%$ (for drugs) and 25\% (for alcohol) of the total number of employees performing safety sensitive functions. Beginning

Abbreviations: DOT, Department of Transportation; FTA, Federal Transit Association; RIA, Regulatory Impact Analyses. 
in 1998, the number of random tests for alcohol was changed to at least $10 \%$ of the total number of employees performing safety sensitive functions. ${ }^{8}$ Post crash testing is required for fatalities, and for non-fatal crashes that meet FTA defined conditions, unless the employee's performance can be discounted as a contributing factor. Testing is to be administered as soon as possible but no later than eight hours after the crash for alcohol and 32 hours for drugs. ${ }^{11}$

Regarding drug use, the regulations specify that safety sensitive employees and contractors may not use any of five prohibited substances (or their metabolites), including marijuana, cocaine, opiates, amphetamines, or phencyclidine (PCP). Drugs tests are performed through urinalysis. The DOT reports do not indicate whether or not confirmatory drug tests were done using gas chromatography. Percent positive drug test results are based on the number of positive results divided by the number of specimens collected. ${ }^{5}$

Alcohol screening tests are conducted with either a saliva testing device or a non-evidential breath testing device. If screening tests indicate an alcohol concentration of 0.02 or greater, a confirmation test using an evidential breath testing device is performed. The confirmation test must be conducted using an evidential breath testing device which is listed on the Conforming Product List of the National Highway Transportation Safety Administration (NHTSA). ${ }^{5}$ The regulations specify that consumption is prohibited under the following circumstances: (1) four hours before performing a safety sensitive function; (2) while performing a safety sensitive function; (3) after a fatal crash (unless the employee has received a post crash test or eight hours have elapsed, whichever occurs first); and (4) after a non-fatal crash (unless the employee's involvement can be completely discounted as a contributing factor in the crash, the employee has been tested, or eight hours have elapsed).

\section{Test refusals and failures}

From 1996-2000, refusal rates for drug tests were less than $1 / 10$ of $1 \%$ of all attempted tests (drug refusal rate for 1995 not available). For alcohol testing, the refusal rate from 19952000 ranged from $0.10 \%$ to $0.24 \%$ of all attempted tests. ${ }^{5-10}$ The penalty for testing refusal is immediate removal from duty. An employee who fails a drug test is immediately removed from their safety sensitive position, informed of available education and treatment programs, and is referred to a substance abuse professional to determine whether the employee has a drug problem. Depending on company/ agency policy, the employee must complete a course of treatment prescribed by the substance abuse professional and take a return-to-duty drug test with a verified negative result in order to return to their safety sensitive position.

An employee who fails an alcohol test with an alcohol concentration of 0.02 or greater but less than 0.04 must be removed from duty for eight hours or until a retest shows an alcohol concentration of less than 0.02. An employee with an alcohol concentration of 0.04 or greater must be prohibited from performing any safety sensitive duties, removed from their position, and be evaluated by a substance abuse professional to determine if they have an alcohol problem. To return to a safety sensitive position, the employee must properly complete a course of treatment prescribed by the substance abuse professional and pass a return-to-duty alcohol test.

\section{DATA ANALYSIS}

\section{Outcome measures}

The relative risk (RR) and 95\% confidence interval (CI), population attributable risk (PAR), and population attributable risk percentage (PAR\%) were calculated as described below. The $95 \%$ confidence interval (CI) was calculated for each RR, PAR, and PAR\% (unless the RR is less than one, in which case the PAR and PAR\% are not calculated). ${ }^{12}$ These estimates, and the estimated number attributable to alcohol or drugs per 1000 crashes in the US transit industry from 1995-2000, are shown in tables 1 and 2, respectively. In table 3 , we apply the PAR estimates to the actual number of transit industry crashes that occurred from $1995-2000^{13}$ to estimate the number of crashes attributable to alcohol or drugs in the US transit industry. Crashes are defined as collisions with other vehicles, objects, and people (except suicides), and derailments/buses going off the road. ${ }^{13}$

\section{Calculation of the population attributable risk}

The population attributable risk (PAR) is the incidence in the population that is associated with, or can be attributed to, exposure to a specified risk factor. ${ }^{14}$ This is expressed as a percentage,

$$
P A R \%=\frac{P_{e} \times(R R-1)}{1+P_{e} \times(R R-1)} \times 100
$$

where $P_{e}$ is the proportion of controls exposed to alcohol, and where $R R$ is the relative risk for those exposed to alcohol compared to those not exposed, that is:

$$
R R=\frac{P(\text { crash } \mid \text { alcohol })}{P(\text { crash } \mid \text { no-alcohol })}
$$

There is no direct estimate of the crash rate for operators, whether impaired by alcohol or not-that is, $P$ (crash $\mid$ alcohol) or $P$ (crash $\mid$ no-alcohol). However, from post crash testing, we have an estimate of $P$ (alcohol|no-crash). From random testing, we have an estimate of $P$ (alcohol|no-crash). When the occurrence of an event is low, such as in the case of transit crashes, the odds ratio provides a very good estimate of the relative risk, ${ }^{15}$ which is calculated as follows:

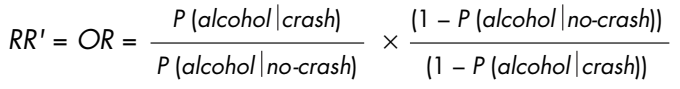

\section{RESULTS}

\section{Population attributable risk for alcohol in relation to} transit crashes

Table 1 summarizes the number and proportion of transit employees who underwent random or post crash alcohol testing from 1995-2000. The proportion testing positive for post crash and random testing ranged from 0.0004 to 0.0020 , and from 0.0010 to 0.0017 , respectively.

As the RR was greater than or equal to one during 1995 and 1999, the PAR, PAR\%, and number attributable to alcohol per 1000 crashes were calculated for those two years only. For 1995, the PAR\% was $0.03 \%$, and for 1999, the PAR\% was $0.016 \%$. As table 1 shows, less than one crash per 1000 could be attributed to alcohol for either year.

\section{Population attributable risk for drugs in relation to transit crashes}

Table 2 summarizes the number and proportion of transit employees who underwent random or post crash drug testing from 1995-2000. A greater proportion of employees tested positive for random and post crash drug use compared to alcohol. The proportion testing positive for post crash and random drug testing ranged from 0.0095 to 0.0217 . The 1995 proportion of 0.0217 , for example, represents about 22 positives for each 1000 post crash tests, and 0.0173 represents 
Table 1 Estimated relative risk, 95\% confidence intervals, and population attributable risk (PAR) of alcohol for crashes, US transit industry, 1995-2000

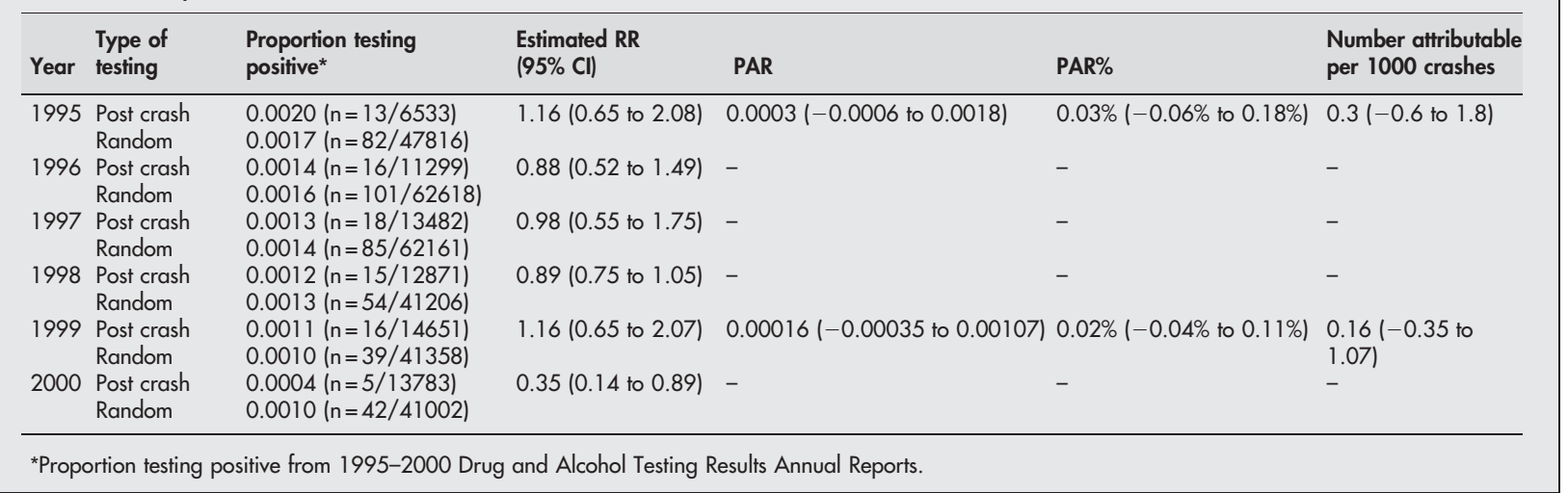

about 18 positives for each 1000 random tests. The number of crashes attributable to drugs per 1000 crashes from 19952000 ranged from 3.8 in 1998 to 6.7 in 1997.

\section{Estimated number of transit industry crashes attributable to alcohol and drugs}

Table 3 (available at http://www.injuryprevention.com/ supplemental) shows the number of crashes in the transit industry from $1995-2000^{13}$ and, using the PAR\% calculation, the estimated number attributable to alcohol, drugs, or either alcohol or drugs. Annual number of crashes ranged from 23310 (1999) to 25683 (1995). The estimated number of crashes attributable to either alcohol or drugs ranged from 91 (1998) to 167 (1997).

\section{DISCUSSION}

Based on 1995-2000 data, our calculation of PAR\% shows that the estimated percentage of transit crashes attributable to employee alcohol and drug use was very low for alcohol and only somewhat higher for drugs. The only previous estimates of transit industry alcohol and drugs use were published in the Regulatory Impact Analyses (RIA) ${ }^{416}$ and assumed that the proportion of crashes due to alcohol or drugs was proportional to the rate of post crash positive tests-that is, $1.85 \%$ for alcohol and $4.08 \%$ for drugs. These figures were used to project benefits from testing, calculated in terms of the anticipated reduction in injuries from crashes caused by transit operators under the influence of alcohol or drugs. This assumption, of course, did not account for the "control" operators - that is, those who had positive levels of alcohol or drugs but were not involved in a crash. Therefore, the 1994 RIA of the Regulations on Prevention of Prohibited
Drug Use and Alcohol Misuse (49 CFR 643 and 654, respectively) probably represents an overestimate of the proportion of crashes attributable to alcohol and drugs during the pretesting period. As neither post crash nor random tests were collected under standardized conditions during this period, the degree of overestimation is unknown. After testing began, when adequate data were available, both the percent testing positive and the risk of crashes attributable to drug or alcohol involvement were small. This was true in 1995, considered to be the "baseline" year, ${ }^{11}$ and in 2000, the sixth year of the policy. From 1995-2000, there were 10 fatalities that resulted from crashes in which there was a positive drug test; there were no fatalities from crashes in which there was a positive alcohol test. ${ }^{10}{ }^{11}$

Regarding limitations, it is not possible to determine whether involvement of alcohol or drugs was higher in crashes resulting in injury or death than in crashes resulting in property damage. Likewise, blood alcohol content information was not available. As there was no specific drug and alcohol testing legislation in Europe, and little reliable information available on workplace testing that was performed, ${ }^{23}$ it is not possible to compare US transit employees with European workers. Likewise, Canada does not have mandatory workplace alcohol and drug testing. ${ }^{24}$

In terms of potential biases, the PAR\% estimates depend on the validity of the post crash and random testing results. Bias in testing favoring either higher or lower results could yield different PAR\% estimates. Bias in the estimates could be generated from selection bias in the choice of individuals tested, in laboratory analyses of results, or in reporting biases from the individual transit agencies. The DOT reports indicate no reason to suspect systematic bias in the testing. The

Table 2 Estimated relative risk, 95\% confidence intervals, and population attributable risk (PAR) of drugs for crashes, US transit industry, 1995-2000

\begin{tabular}{|c|c|c|c|c|c|c|}
\hline Year & Type of testing & Proportion testing positive* & $\begin{array}{l}\text { Estimated RR } \\
(95 \% \mathrm{Cl})\end{array}$ & PAR & PAR $\%$ & $\begin{array}{l}\text { Number attributable } \\
\text { per } 1000 \text { crashes }\end{array}$ \\
\hline 1995 & $\begin{array}{l}\text { Post crash } \\
\text { Random }\end{array}$ & $\begin{array}{l}0.0217(n=147 / 6783) \\
0.0173(n=1390 / 80439)\end{array}$ & $1.26(1.06$ to 1.50$)$ & $0.0045(0.0010$ to 0.0086$)$ & $0.45 \%(0.10 \%$ to $0.86 \%)$ & 4.5 (1.04 to 8.58$)$ \\
\hline 1996 & $\begin{array}{l}\text { Post crash } \\
\text { Random }\end{array}$ & $\begin{array}{l}0.0209(n=256 / 12254) \\
0.0149(n=1620 / 108347)\end{array}$ & 1.41 (1.24 to 1.61$)$ & $0.0061(0.0036$ to 0.0090$)$ & $0.61 \%(0.36 \%$ to $0.90 \%)$ & $6.1(3.6$ to 9.0$)$ \\
\hline 1997 & $\begin{array}{l}\text { Post crash } \\
\text { Random }\end{array}$ & $\begin{array}{l}0.0187(n=260 / 13876) \\
0.0121(n=1295 / 107047)\end{array}$ & 1.56 (1.36 to 1.78$)$ & $0.0067(0.0043$ to 0.0093$)$ & $0.67 \%(0.43 \%$ to $0.93 \%)$ & 6.7 (4.3 to 9.3$)$ \\
\hline 1998 & $\begin{array}{l}\text { Post crash } \\
\text { Random }\end{array}$ & $\begin{array}{l}0.0145(n=203 / 13968) \\
0.0107(n=1196 / 111490)\end{array}$ & $1.36(1.17$ to 1.58$)$ & $0.0038(0.0018$ to 0.0062$)$ & $0.38 \%(0.18 \%$ to $0.62 \%)$ & $3.8(1.8$ to 6.2$)$ \\
\hline 1999 & $\begin{array}{l}\text { Post crash } \\
\text { Random }\end{array}$ & $\begin{array}{l}0.0152(n=230 / 15170) \\
0.0100(n=1198 / 119753)\end{array}$ & 1.52 (1.22 to 1.89$)$ & $0.0052(0.0022$ to 0.0088$)$ & $0.52 \%(0.22 \%$ to $0.88 \%)$ & $5.2(2.2$ to 8.8$)$ \\
\hline 2000 & $\begin{array}{l}\text { Post crash } \\
\text { Random }\end{array}$ & $\begin{array}{l}0.0159(n=240 / 15012) \\
0.0095(n=1151 / 121668)\end{array}$ & 1.70 (1.48 to 1.96$)$ & $0.0066(0.0045$ to 0.0090$)$ & $0.66 \%(0.45 \%$ to $0.90 \%)$ & $6.6(4.5$ to 9.0$)$ \\
\hline
\end{tabular}


number of tests conducted was below that projected, but there were no indications that testing favored those more or less likely to test positive, either for post crash or random testing.

If the false negative rate was the same for random and post crash testing, then the RR would not be affected. The bias, however, would have an effect on attributable fraction estimates through an effect on prevalence of exposure for the control population; the impact is roughly proportional to the magnitude of bias in the prevalence estimate. Therefore, a $5 \%$ underestimate in the positive rate would result in an approximate 5\% underestimate in the PAR\%; likewise, a 5\% overestimate in the positive rate results in an approximate $5 \%$ overestimate in the PAR\%.

Based on examination of FTA data, there are apparently no biases in the data collection that would have substantially affected the results of this study; the conclusion that drugs and alcohol account for a very small percentage of crashes, injury, and death for the years examined in the transit industry appears warranted. If alcohol and drug use account for less than $1 \%$ of all transit crashes, the causes of the remaining $99 \%$ need to be addressed. Other possible contributing factors for transit crashes include fatigue due to sustained attention, shift type, and shift duration, lack of rest breaks, and long hours of uninterrupted driving. ${ }^{17-21}$ The road environment may be an important contributing factor in transit crashes. Analyses of low speed crashes in public transport show that the majority of events happen while pulling into a bus stop. ${ }^{22}$ The emphasis on drugs and alcohol does little to address the many underlying causes of transit crashes, and may serve to deflect attention and resources away from investigating and addressing other causes.

It is plausible, however, that the introduction of random testing in the transportation industry discouraged commercial drivers from substance use and further reduced the prelegislation low post crash testing positive rates. The preventive effect of mandatory testing is difficult to show because various environmental factors can have an influence on crash rates. Research evidence on the deterrent effect of testing on crash rates in commercial driving is scarce and inconclusive, and usually based on poorly controlled studies. For example, analyses of fatalities among commercial truck drivers from 1982 to 1997 failed to show a significant sustained decrease in crashes after the introduction of a testing program. ${ }^{25}$ Conversely, Taggart presented data that demonstrated a tenfold reduction in human factor train crashes between 1983 and 1988 coincident with the onset of a drug testing program at the Southern Pacific Railroad. ${ }^{26}$

Our results for transit employees regarding alcohol contrast with results for the general driving population, where alcohol involvement for all collisions is estimated at about $10 \%$, and for fatal collisions is about $40 \%{ }^{27}$ The situations are not directly comparable, because transit employees operate in a public setting with a high level of training and experience. As our results show the attributable risk for alcohol and transit crashes was low before random testing was implemented, it is not possible to extrapolate the potential impact of random testing to the general population. Nevertheless, lower attributable risk for alcohol in relation to general population traffic collisions may be achievable by increasing awareness of the dangers of and decreasing the acceptability of drinking while driving. As there are no good estimates for attributable risk of drugs on general population traffic crashes; comparisons would be misleading. However, our results suggest that very low levels can be achieved.

\section{CONCLUSION}

An FTA Drug and Alcohol Program assessment conducted by the DOT concludes that mandatory testing has resulted in a

\section{Key points}

- Our aim was to estimate the number and percentage of crashes that could be attributed to alcohol or drugs through calculation of the population attributable risk (PAR) using federally mandated drug and alcohol testing results.

- For alcohol, results indicate that less than one crash in 1000 could be attributed to alcohol during 19952000. For drugs, results indicate that $4-6$ crashes per 1000 could be attributed to drugs annually between 1995 and 2000.

- Approaches to transit safety based on reducing employee use of alcohol and drugs have modest potential for reducing crashes.

safer public transportation system. ${ }^{11}$ The FTA program may have heightened awareness among transit employees about adverse safety and personal consequences of substance use, and in this way contributed to public safety. Given the low proportion of crashes attributable to alcohol or drugs, however, the results of the current analysis suggest that approaches to transit safety based primarily on reducing alcohol and drug use have limited potential for reducing crashes. Overly optimistic assessments about the potential benefits of drug and alcohol testing for reducing crashes should not detract from other approaches.

\section{ACKNOWLEDGEMENTS}

This work was funded in part by a grant from the Robert Wood Johnson Foundation (Evaluation of National Drug and Alcohol Testing in Safety Sensitive Employees in the Mass Transit Industry) and the National Institute on Alcoholism and Alcohol Abuse under Grant \#RO1-AA8949 (Worksite-related Alcohol Behavior in Urban Transit Drivers).

\section{Authors' affiliations}

C B Cunradi, M Klein, Prevention Research Center, Pacific Institute for Research and Evaluation, Berkeley, CA, USA

D R Ragland, University of California Traffic Safety Center, Institute of Transportation Studies and School of Public Health, University of California at Berkeley, Berkeley, CA, USA

B Greiner, Department of Epidemiology and Public Health, University College Cork, Cork, Republic of Ireland

J M Fisher, Trauma Foundation, San Francisco General Hospital, San Francisco, CA, USA

Competing interests: none.

Ethics committee approval: this report was based on secondary analysis of previously published federal data that is available to the public. No ethics committee approval was therefore required.

\section{REFERENCES}

1 Peele S. Asleep at the switch. Reason 1991:63-65.

2 Senate Committee on Commerce Science and Transportation. Omnibus transportation employee testing act of 1991, Report of the Senate Committee on Commerce, Science, and Transportation. Washington, DC: US Government Printing Office, 1991 May 2, 1991, Report no 102-54.

3 Federal Transit Administration. Implementation guidelines for drug and alcohol regulations in mass transit. Washington, DC: Federal Transit Administration, Department of Transportation, 1994 April 1994, Report no FTA-OH-26-0001-94-1.

4 Federal Transit Administration. regulatory impact analysis of regulation on prevention of alcohol use in transit operations (49 CRF 654). Washington, DC: Federal Transit Administration, US Department of Transportation, 1994 January 12, 1994.

5 Ault J, Berty P, Browning K, et al. Drug and alcohol testing results 1995 annual report. Washington, DC: U, S.Department of Transportation, Federal Transit Administration, Office of Technical Assistance and Safety, 1997 March 1997. Report no FTA-MA-18X018-97-1, DOT-VNTSC-FTA-97-2. 
6 Ault J, Center B, David R, et al. Drug and alcohol testing results 1996 annual report. Washington, DC: US Department of Transportation, Federal Transit Administration, Office of Technical Assistance and Safety; 1997, Report no DOT-VNTSC-FTA-98-2, FTA-MA-18X018-98-1.

7 Nicholas D, Anderson R, Redington M, et al. Drug and alcohol testing results 1997 annual report. Washington, DC: U, S.Department of Transportation, Federal Transit Adminstration, Office of Safety and Security, 1998. Report no DOT-VNTSC-FTA-98-7, FTA-MA-26-5001-98-1.

8 Harrison J, Anderson R, Redington M, et al. Drug and alcohol testing results 1998 annual report. Washington, DC: U S.Department of Transportation, Federal Transit Administration, Office of Safety and Security, 1999. Report no DOT-VNTSC-FTA-99-6, FTA-MA-26-5010-99-01

9 Anderson R, Baker B, Redington M, et al. Drug and alcohol testing results 1999 annual report. Washington, DC: US Department of Transportation, Federal Transit Administration, Office of Safety and Security, 2000, Report no DOT-VNTSC-FTA-00-06, FTA-MA-26-5010-00-1

10 Anderson R, Baker B, Buchanan R, et al. Drug and alcohol testing results 2000 annual report. Washington, DC: US Department of Transportation, 2001.

11 Powers J. FTA Drug and alcohol program assessment. Washington, DC: US Department of Transportation, Federal Transit Administration, Office of Safety and Security, 2002, Report no DOT-VNTSC-FTA-02-11; FTA-MA-26-501002-2.

12 Sahai H, Kurshid A. Statistics in epidemiology: methods techniques and applications. Boca Raton: CRC Press, 1996.

13 U. S. Department of Transportation. National transportation statistics 2002 Washington, DC: Bureau of Transportation Statistics, US Government Printing Office, 2002, Report no BTS02-08.

14 Last JM, Abramson JH. A dictionary of epidemiology, 3rd edn. New York: Oxford University Press, 1995.
15 Fleiss JL. Statistical methods for rates and proportions, 2d edn. New York: Wiley, 1981

16 Federal Transit Administration. Regulatory impact analysis of regulation on prevention of drug use in transit operations (49 CRF 653). Washington, DC: Federal Transit Administration, US Department of Transportation, 12 January, 1994.

17 Connor J, Whitlock G, Norton R, et al. The role of driver sleepiness in car crashes: a systematic review of epidemiological studies. Accid Anal Prev 2001;33:31-41

18 Edkins GD, Pollock C. The influence of sustained attention on railway accidents. Accid Anal Prev 1997;29:533-9.

19 Fell DL, Black B. Driver fatigue in the city. Accid Anal Prev 1997;29:463-9.

20 MacDonald I, Smith L, Lowe S, et al. Effects on accidents of time into shift and of short breaks between shifts. Int J Occup Environ Health 1997;3(Suppl 2):S40-S45.

21 Pokorny ML, Blom DH, Van Leeuwen P. Shifts, duration of work and accident risk of bus drivers. Ergonomics 1987;30:61-88.

22 af Wahlberg A. Characteristics of low speed accidents with buses on public transport. Accid Anal Prev 2002:34:637-47.

23 Verstraete AG, Pierce A. Workplace drug testing in Europe. Forensic Sci Int 2001;121:2-6.

24 Canadian Human Rights Commission. Canadian Human Rights Commission policy on alcohol and drug testing. Ottawa: Canadian Human Rights Commission, 2002

25 Swena DD, Gaines W Jr. Effect of random drug screening on fatal commercial truck accident rates. International Journal of Drug Testing 1999;2:1-13.

26 Taggart RW. Results of the drug-testing program of the Southern Pacific Railroad. In: Drugs in the workplace: research and evaluation data. Rockville, MD: National Institute on Drug Abuse, 1989.

27 Evans L. Traffic safety. Bloomfield Hills, MI: Science Serving Society, 2004. 